\title{
Evaluation of Speech, Spatial Perception and Hearing Quality in Unilateral, Bimodal and Bilateral Cochlear Implant Users
}

\author{
Büşra Koçak Erdem ${ }^{1}$ (D), Ayça Çiprut ${ }^{2}$ (D) \\ Original Investigation $>{ }^{1}$ Department of Audiology, Lütfi Kırdar Training and Research Hospital, İstanbul, Turkey \\ ${ }^{2}$ Department of Audiology, Marmara University School of Medicine, İstanbul, Turkey
}

Abstract

ORCID IDs of the authors:

B.K. E. 0000-0003-3017-0361;

A.Ç. 0000-0002-0295-8760.

Cite this article as: Koçak Erdem B, Ciprut A. Evaluation of Speech, Spatial Perception and Hearing Quality in Unilateral, Bimodal and Bilateral Cochlear Implant Users. Turk Arch

Otorhinolaryngol 2019; 57(3): 149-53.

This study was presented at the $14^{\text {th }}$ Turkish Rhinology Congress, $6^{\text {th }}$ National Neurootology Congress, $2^{\text {nd }}$ Head and Neck Congress, May 2018, Antalya, Turkey

\section{Corresponding Author:}

Büşra Koçak Erdem; 1busrakocak@gmail.com

Received Date: 01.02.2019

Accepted Date: 02.04.2019

Content of this journal is licensed under a Creative Commons Attribution 4.0 International License. Available online at www.turkarchotolaryngol.net
Objective: The aim of the study was to conduct a scale-based evaluation of the hearing skills of unilateral, bimodal and bilateral cochlear implant (CI) users, including distinguishing, orientating and locating speech and environmental sounds in their surrounding environment that they are exposed to in different contexts of everyday life. The scale results were compared between groups.

Methods: A total of 74 cochlear implant users, 30 unilateral, 30 bimodal and 14 bilateral, were included in the study. Their ages ranged from 11 to 64 years. Participants were assessed using the Speech, Spatial and Qualities of Hearing Scale (SSQ).

Results: Bilateral CI users' subjective ratings of their own hearing skills were found to be significantly bet- ter than those of bimodal and unilateral CI users; bimodal users' subjective ratings were also found to be significantly better than those of unilateral CI users. Paired comparisons showed statistically significant differences between the groups in terms of total scores of Speech, Spatial, Qualities of Hearing and General SSQ $(p<0.05)$.

Conclusion: Our findings show that bilateral use of cochlear implants should be recommended for those presently using bimodal and unilateral devices. Moreover, subjective tests should be used regularly along with objective tests for evaluating CI patients.

Keywords: Cochlear implant, speech perception, spatial hearing, hearing quality

\section{Introduction}

The auditory system not only serves to hear speech, but also performs a range of functions such as discriminating the different sounds in the surrounding environment and identifying their localization. People use their sense of hearing to identify and define the events both in their daily listening environments and in their recreational activities such as listening to music $(1,2)$.

When listeners need to engage in conversations that include several speakers with similar voices, they need to use their selective attention to follow the flow of the conversation. In order to be able to shift one's attention from one conversation to another and to be able to follow multiple simultaneous speech streams, it is important to make use of the cues pertaining to time and space that are provided by the auditory world, and binaural hearing strong- ly influences the skills to do so. As is the case in persons with normal hearing, the binaural system is extremely important also in persons who use hearing aid and/or cochlear implant (CI), in order to be able to combine auditory cues and to perform the mentioned functions. Binaural hearing results from a process in which the input from the two ears is processed and combined in the auditory pathway and encoded in a manner that can be perceived by the listener. When listening with one ear it is very difficult to understand where the sound is coming from (3-5). Binaural hearing supports speech comprehension in noisy environments. It enables to segregate the target sound by using the time and intensity difference between the ears or the spatial cues, especially in the presence of noise $(6,7)$.

Bilateral CI has become widespread due to the benefits of binaural hearing. In an evaluation of 
adult patients who underwent bilateral $\mathrm{CI}$ at the same time or at different times, speech discrimination, sound localization and quality of hearing in a noisy environment were found to be better than those who use unilateral CI (8).

Evaluating speech performance after cochlear implantation is crucial, and there are various methods for this evaluation. In many CI centers evaluations are performed with hearing tests. Clinically applied speech comprehension and localization tests are time-consuming and raise questions as the conditions under which these tests are applied do not fully represent the listening conditions of daily life. Subjective tests (questionnaires and/ or rating scales) are easy to perform and allow to collect large amounts of data in a short time. Moreover, today, the subjective experiences of the patient gain ever-more importance in health evaluations. It is possible to identify the individual position of the patient in terms of real-world functioning and quality of life using the results of the studies examining the effects of $\mathrm{CI}$ on daily life $(9,10)$.

In the light of these information, in our study, we aimed to identify the qualities of the basic skills of unilateral, bimodal and bilateral CI users, such as speech and hearing, segregating, localizing environmental sounds in daily life. The study aimed to investigate whether there are differences in the hearing quality, speech perception and spatial hearing among the user groups.

\section{Methods}

The study was conducted at the Marmara University School of Medicine Ethical Committee approval was obtained on $8^{\text {th }}$ December 2017 with protocol number 09.2017.716. Written informed consent was obtained from the patients, or from their parents or legal guardians if the patient was younger than 18 years of age.

Seventy-four individuals aged from 11 to 64 years who underwent a CI procedure at the Marmara University School of Medicine or in an external center took The Speech, Spatial and Qualities of Hearing Scale (SSQ). Thirty of the participants were unilateral $\mathrm{CI}$ users, 30 were bimodal $\mathrm{CI}$ users, and 14 were bilateral CI users. All participants had severe or profound sensorineural bilateral hearing loss and used CI in one ear for at least six months. None of the participants had any physical or psychological disability apart from hearing loss. All participants were literate. Ten participants aged under 18 years answered the questions themselves under the supervision of their parent or guardian, and no adjustments were made on the scale for these young participants.

The Speech, Spatial and Qualities of Hearing Scale (SSQ) was developed by Noble and Gatehouse (11) in 2004 and adapted and normalized for Turkish by K1lıç (12). Questions included in the SSQ Scale are grouped under three sections.

1- Speech Perception (SP): The questions in this section depict the real-world conditions of listening environments. Basing on the difficulties posed by such conditions, the questions involve the positions of competing sounds, the visibility of all speakers participating in the conversation, the number of persons involved, and the characteristics of the environment. Some of the items aim to identify the functioning of the binaural hearing system. These involve the ability to be selective and fast, such as disregarding other voices or sounds while paying attention to a particular one, focusing on the targeted conversation, and following the conversation as it quickly moves from one speaker to another.

2- Spatial Hearing (SH): Taking into account the basic components of direction and distance, the questions of this section extend to cover the discrimination of the movement component.

3- Hearing Quality (HQ): The questions address the clarity, naturalness and recognition of the voices, and the listening effort put in to follow the conversation. The questions in this section use examples of music and speaking voices, i.e., sounds that are frequently encountered in everyday life. Detecting the mood of another person from their voice is a major issue addressed in this section.

The questionnaire consists of 49 questions that are divided into three sections: The SP section consists of 14 questions, the $\mathrm{SH}$ section of 17 questions, and the HQ section of 18 questions. Participants are asked to respond on a scale of 0 to 10 and rate the quality of their hearing by envisioning the situation described in the questions and their attitude in such situations. Higher scores indicate better skills. The overall SSQ Score is calculated by dividing the total points by the number of questions, and the SP, $\mathrm{SH}, \mathrm{HQ}$ scores are calculated by dividing the total points rated by the number of questions in the section $(11,12)$.

In our study, unilateral, bimodal and bilateral CI users were comparatively evaluated in terms of the components of the scale and in terms of their overall SSQ scores compared to the group total.

The participating unilateral, bimodal and bilateral CI users were asked to subjectively rate themselves for SP, SH and HQ based on the SSQ Scale. Prior to data analysis, all data were verified for normal distribution and decision was made whether to use the parametric or the non-parametric statistical technique based on the result. The Shapiro-Wilk Test was used to verify the normality of the data.

The Fisher's Exact test was used to comparatively assess the categorical data at a significance level of $\mathrm{p}<0.05$. Results were shown in numbers and percentages. Inter-group comparisons of continuous variables were performed using the non-parametric Kruskal-Wallis test since the variables did not show a normal distribution. Variables that showed significant difference were tested with the Bonferroni correction to eliminate errors of the first kind. Statistical analyses were performed using the SPSS Statistics Version 17.0 (IBM Corp., NY, USA) software package. 


\section{Results}

The unilateral CI users group included 17 female and 13 male participants, the bimodal CI users group 14 female and 16 male participants, and the bilateral CI users group seven female and seven male participants. Gender was not found statistically significant for the classification of education and hearing loss in terms of language development ( $p>0.05)$ (Table 1$)$.

Age and total period of CI use (months) were not found statistically significant in terms of SP, SH and HQ scores (p0.05) (Table 2).

Statistical analyses based on SP, SH and HQ scores showed statistical significance with a mean SP score of 4.64 for unilateral CI users, 5.96 for bimodal CI users, and 8.14 for bilateral CI users $(\mathrm{p}<0.001)$. Mean $\mathrm{SH}$ scores were also statistically significant with 3.93 for unilateral CI users, 6.35 for bimodal CI users, and 8.47 for bilateral CI users $(\mathrm{p}<0.001)$. Mean HQ scores were 5 for unilateral CI users, 6.36 for bimodal CI users, and 8.94 for bilateral CI users $(p<0.001)$ and found statistically significant. The Overall SSQ Scores of the groups also showed statistical significance with a mean SSQ score of 4.49 for unilateral CI users, 6.2 for bimodal CI users, and 8.57 for bilateral CI users $(\mathrm{p}<0.001)($ Table 3$)$.
The resulting data were explored using the Kruskal-Wallis test and verified with the Bonferroni method to eliminate type I errors. Statistical significances were found when unilateral and bimodal CI users were compared based on SP, SH, HQ and Overall SSQ Scores $(p<0.05)$. Statistical significances were found when bilateral and bimodal CI users were compared based on SP, SH, HQ and Overall SSQ Scores $(p<0.05)$. Statistical significances were also found when bimodal and bilateral CI users were compared based on SP, SH, HQ and Overall SSQ Scores $(\mathrm{p}<0.05)($ Table 4).

Table 4. Paired Comparisons of Unilateral, Bimodal and speech perception and spatial hearing Qualities of Hearing and Overall SSQ Scores

\begin{tabular}{l|c|c|c|c}
\hline Participants & $\begin{array}{c}\text { Speech } \\
\text { Perception } \\
\text { Score }\end{array}$ & $\begin{array}{c}\text { Spatial } \\
\text { Hearing } \\
\text { Score }\end{array}$ & $\begin{array}{c}\text { Hearing } \\
\text { Quality } \\
\text { Score }\end{array}$ & $\begin{array}{c}\text { Overall } \\
\text { SSQ } \\
\text { Score }\end{array}$ \\
\hline Unilateral-Bimodal & 0.037 & 0.005 & 0.003 & 0.011 \\
\hline Unilateral-Bilateral & $<0.001$ & $<0.001$ & $<0.001$ & $<0.001$ \\
\hline Bimodal-Bilateral & $<0.001$ & $<0.001$ & $<0.001$ & $<0.001$
\end{tabular}

Table 1. Percentiles and frequencies for categorical data

\begin{tabular}{l|l|c|c|c|c}
\hline & & $\begin{array}{c}\text { Unilateral } \\
\text { Number (\%) }\end{array}$ & $\begin{array}{c}\text { Bimodal } \\
\text { Number (\%) }\end{array}$ & $\begin{array}{c}\text { Bilateral } \\
\text { Number (\%) }\end{array}$ \\
\hline \multirow{2}{*}{ Gender } & Female & $17(56.7)$ & $14(46.66)$ & $7(50)$ \\
\hline & Male & $13(43.3)$ & $16(53.33)$ & $7(50)$ \\
\hline \multirow{2}{*}{ Education Level (p) } & Primary-Secondary School & $12(40)$ & $8(26.66)$ & $4(28.66)$ \\
\hline & High school & $13(43.3)$ & $17(56.66)$ & $6(42.66)$ \\
\hline \multirow{2}{*}{$\begin{array}{l}\text { Classification by } \\
\text { Lingual Development }\end{array}$} & University & $5(16.7)$ & $5(16.66)$ & $4(28.66)$ \\
\hline
\end{tabular}

Table 2. Analysis of age and total period of cochlear implant use (months) in unilateral, bimodal and bilateral user groups

\begin{tabular}{l|c|c|c|c|c|c|c|}
\hline \multirow{2}{*}{ Group } & \multicolumn{2}{|c|}{ Unilateral } & \multicolumn{2}{c|}{ Bimodal } & \multicolumn{2}{c}{ Bilateral } \\
\hline Variables & Median (IR) & Min-Max & Median (IR) & Min-Max & Median (IR) & Min-Max & p \\
\hline Age & $29(16)$ & $17-64$ & $27(17)$ & $11-64$ & $22.5(18)$ & $10-52$ & 0.105 \\
\hline Total Period of CI Use (months) & $73.5(104)$ & $7-240$ & $60(67)$ & $6-216$ & $96(39)$ & $36-132$ & 0.082 \\
\hline
\end{tabular}

IR: interquartile range; CI: cochlear implant; Min: minimum; Max: maximum

Table 3. Speech perception, spatial hearing, hearing quality and overall SSQ scores in unilateral, bimodal and bilateral user groups

\begin{tabular}{l|c|c|c|c|c|c|c|}
\hline \multirow{2}{*}{ Group } & \multicolumn{2}{|c|}{ Unilateral } & \multicolumn{3}{|c|}{ Bimodal } & \multicolumn{2}{c}{ Bilateral } \\
\hline Variables & Median (IR) & Min-Max & Median(IR) & Min-Max & Median (IR) & Min-Max & p \\
\hline Speech Perception & $4.64(1.97)$ & $0.79-7.14$ & $5.96(1.97)$ & $1.5-9.31$ & $8.14(1.16)$ & $6.93-9.5$ & $<0.001$ \\
\hline Spatial Hearing & $3.93(2.19)$ & $0.88-6.71$ & $6.35(1.69)$ & $2-8.18$ & $8.47(0.72)$ & $7.24-9.35$ & $<0.001$ \\
\hline Hearing Quality & $5(1.71)$ & $2.67-7.67$ & $6.36(2.07)$ & $3.5-9.06$ & $8.94(1.19)$ & $7.67-10$ & $<0.001$ \\
\hline Overall SSQScore & $4.49(1.77)$ & $2.6-6.53$ & $6.21(1.63)$ & $3.39-8.67$ & $8.57(0.59)$ & $7.45-9.27$ & $<0.001$
\end{tabular}

IR: interquartile range; SSQ: Speech; Spatial and Qualities of Hearing Scale 


\section{Discussion}

In our study, no statistically significant differences were found among the unilateral, bimodal and bilateral CI user groups in terms of lingual development based on chronological age, total period of CI use, gender, education level and hearing loss classification.

Studies that report to have compared unilateral and bilateral CI users with objective and subjective tests were conducted with patient groups who experienced hearing loss in the post-lingual period (10, 13-15). In Turkey, bilateral cochlear implants are generally not widely used in adult patients because these have a high cost and are not covered by social security except under certain circumstances. Therefore, our study included fewer adult bilateral CI users than adult bimodal and unilateral CI users. This is the major limitation of our study.

Although cochlear implants are successful in providing qualified auditory inputs in people with severe/profound hearing loss, they also have some limitations. The first of these limitations is the lack of ability to detect and discriminate signals coming from independent sources when $\mathrm{CI}$ is used in one ear in individuals whose hearing loss is profound in both ears. This limitation leads to difficulties in listening to the conversation in the presence of competing signals. Unilateral CI users should be encouraged to opt for bilateral CI in order to relieve them of part of these functional difficulties that they encounter when they try to localize the sounds in the environment $(16,17)$. Despite the known benefits of using bilateral CIs, The Turkish Social Security Institution still pays only for a unilateral $\mathrm{CI}$ in adult patients and permits bilateral implantation only under special circumstances. Therefore, it is important that individuals who cannot afford to pay for the second CI themselves wear a hearing aid on the unimplanted ear to support binaural hearing.

The questions in the SP, SH, HQ sections of the SSQ inquire about the quality of hearing speech, the acoustic characteristics of the environment, the localization of objects and people, the clarity and naturalness of the sounds heard in the context of their everyday surroundings (18). In the SSQ, where users self-rated their speech perception, spatial hearing and hearing quality, SP, SH, HQ and overall SSQ scores of bilateral CI users were better than those of bimodal and unilateral $\mathrm{CI}$ users. And the SP, SH, HQ and overall SSQ scores of bimodal CI users were better than those of unilateral CI users.

Studies $(2,19-22)$ exploring the speech comprehension and the spatial hearing abilities of bilateral CI users in the presence of multiple stimuli have found that bilateral CI users achieved better results compared to unilateral CI users. Bilateral CI users are reported to perform better in speech discrimination and sound localization in noisy environments compared to unilateral and bimodal CI users $(16,23,24)$.

A study which investigated the correlation between subjective and objective hearing tests in bilateral and unilateral CI users found a significant moderate correlation between the speech hearing test and the SP section of the SSQ, as well as the localization test and the SH section of the SSQ(10).

Another study examined the localization ability of 22 adult bilateral cochlear implant users with post-lingual hearing loss (25). Localization performance was first measured unilaterally in each ear by alternately activating the devices and then by activating the devices in both ears. Localization ability was found to be better than coincidental localization when both implants were active. Localization was seen to be coincidental when one of the two devices were deactivated. Because of their binaural hearing experience, bilateral CI users were unable to achieve the adequate localization level with a single implant.

There are studies in the literature comparing the hearing quality of unilateral and bilateral CI users $(2,10)$. The results of our study are comparable to the results reported in the literature for the subjective evaluation of hearing quality in unilateral and bilateral CI users.

\section{Conclusion}

The self-ratings of $\mathrm{CI}$ users showed that bilateral CI users performed statistically significantly better in terms of speech perception, spatial hearing and hearing quality compared to bimodal and unilateral CI users; and bimodal CI users performed statistically significantly better in these respects compared to unilateral CI users. Therefore, unilateral CI users should be recommended to use a CI device also in the contralateral ear, or in cases which a second CI procedure is not possible, to wear a hearing aid on this ear. Bimodal CI users should also be recommended to use bilateral CI devices.

In the light of the results of our study, we suggest that clinicians should consider explaining to patients and patient families the functions of binaural hearing, hence the importance of a bilateral hearing aid or bilateral CI to enable improved binaural hearing.

Our study results are based on the personal hearing experiences of CI users. We recommend clinicians who follow-up on CI users to regularly apply questionnaires or scales that evaluate the personal hearing experiences of their patients.

Ethics Committee Approval: Ethics committee approval was received for this study from the Marmara University School of Medicine Ethical Committee (Approval Date: 08.12.2017, Protocol No: 09.2017.716).

Informed Consent: Written informed consent was obtained from the patients, and from their parents and legal guardians if the patient was younger than 18 years of age.

Peer-review: Externally peer-reviewed.

Author Contributions: Concept - B.K.E., A.Ç.; Design - B.K.E., A.Ç.; Supervision - A.Ç.; Resource - B.K.E., A.Ç.; Materials - B.K.E., A.Ç.; Data Collection and/or Processing - B.K.E., A.Ç.; Analysis and/ or Interpretation - B.K.E., A.Ç.; Literature Search - B.K.E.; Writing B.K.E.; Critical Reviews - B.K.E., A.Ç.

Conflict of Interest: The authors have no conflicts of interest to declare. 
Financial Disclosure: The authors declared that this study has received no financial support.

\section{References}

1. Litovsky RY, Parkinson A, Arcaroli J. Spatial hearing and speech intelligibility in bilateral cochlear implant users. Ear Hear 2009; 30: 419-31. [CrossRef]

2. Noble W, Tyler RS, Dunn CC, Bhullar N. Younger-and older-age adults with unilateral and bilateral cochlear implants: Speech and spatial hearing self-ratings and performance. Otol Neurotol 2009; 30: 921-9. [CrossRef]

3. Searle CL, Braida LD, Davis MF, Colburn HS. Model for auditory localization. J Acoust Soc Am 1976; 60: 1164-75. [CrossRef]

4. Blauert J. Spatial Hearing. The Psychophysics of Human Sound Localization. Revised ed. Massachusetts, MA: The MIT Press; 1996

5. Hawley ML, Litovsky RY, Colburn HS. Speech intelligibility and localization in a multi-source environment. J Acoust Soc Am 1999; 105: 3436-48. [CrossRef]

6. Hawley ML, Litovsky RY, Culling JF. The benefit of binaural hearing in a cocktail party: Effect of location and type of interferer. J Acoust Soc Am 2004; 115: 833-43. [CrossRef]

7. Culling JF, Hawley ML, Litovsky RY. The role of head-induced interaural time and level differences in the speech reception threshold for multiple interfering sound sources. J Acoust Soc Am 2004; 116: 1057-65. [CrossRef]

8. Noble W, Tyler R, Dunn C, Bhullar N. Unilateral and bilateral cochlear implants and the implant-plus-hearing-aid profile: comparing self-assessed and measured abilities. Int J Audiol 2008; 47: 505-14. [CrossRef]

9. Capretta NR, Moberly AC. Does quality of life depend on speech recognition performance for adult cochlear implant users? The Laryngoscope 2016; 126: 699-706. [CrossRef]

10. Ramakers GG, Smulders YE, van Zon A, Van Zanten GA, Grolman W, Stegeman I. Correlation between subjective and objective hearing tests after unilateral and bilateral cochlear implantation. BMC Ear Nose Throat Disord 2017; 17: 10. [CrossRef]

11. Noble W, Gatehouse S. Interaural asymmetry of hearing loss, speech, spatial and qualities of hearing scale (SSQ) disabilities, and handicap. Int J Audiol 2004; 43: 100-14. [CrossRef]

12. Kılıç N. Normalization and adaptation of "speech, spatial and quality of hearing scale (SSQ) for Turkish language and evaluation of adults with normal hearing and sensorineural hearing loss by SSQ [in Turkish] Gazi University Institute of Health Sciences, MSc Thesis. 2017.
13. Laske RD, Veraguth D, Dillier N, Binkert A, Holzmann D, Huber AM. Subjective and objective results after bilateral cochlear implantation in adults. Otol Neurotol 2009; 30: 313-8. [CrossRef]

14. Gaylor JM, Raman G, Chung M, Lee J, Rao M, Lau J, et al. Cochlear implantation in adults: A systematic review and meta-analysis.JAMA Otolaryngol Head Neck Surg 2013; 139: 265-72. [CrossRef]

15. Lenarz T, Muller L, Czerniejewska-Wolska H, Vallés Varela H, Orús Dotú C, Durko M, et al. Patient-related benefits for adults with cochlear implantation: A multicultural longitudinal observational study. Audiol Neurootol 2017; 22: 61-73. [CrossRef]

16. Sparreboom M, van Schoonhoven J, van Zanten BG, Scholten RJ, Mylanus EA, Grolman W, et al. The effectiveness of bilateral cochlear implants for severe-to-profound deafness in children: A systematic review. Otol Neurotol 2010; 31: 1062-71. [CrossRef]

17. Basura GJ, Eapen R, Buchman CA. Bilateral cochlear implantation: Current concepts, indications, and results. Laryngoscope 2009; 119: 2395-401. [CrossRef]

18. Noble W. Bilateral hearing aids: A review of self-reports of benefit in comparison with unilateral fitting. Int J Audiol 2006; 45: S6371. [CrossRef]

19. Müller J, Schön F, Helms J. Speech understanding in quiet and noise in bilateral users of the MED-EL COMBI 40/40+ cochlear implant system. Ear Hear 2002; 23: 198-206. [CrossRef]

20. Laszig R, Aschendorff A, Stecker M, Müller-Deile J, Maune S, Dillier N, et al. Benefits of bilateral electrical stimulation with the Nucleus Cochlear implant in adults: 6-month postoperative results. Otol Neurotol 2004; 25: 958-68. [CrossRef]

21. Verschuur CA, Lutman ME, Ramsden R, Greenham P, O'Driscoll M. Auditory localization abilities in bilateral cochlear implant recipients. Otol Neurotol 2005; 26: 965-71. [CrossRef]

22. Neuman AC, Haravon A, Sislian N, Waltzman SB, Susan B. Sound-direction identification with bilateral cochlear implants. Ear Hear 2007; 28: 73-82. [CrossRef]

23. Berrettini S, Baggiani A, Bruschini L, Cassandro E, Cuda D, Filipo R, et al. Systematic review of the literature on the clinical effectiveness of the cochlear implant procedure in adult patients. Acta Otorhinolaryngol Ital 2011; 31: 299-310.

24. Grantham DW, Ashmead DH, Ricketts TA, Labadie RF, Haynes DS. Horizontal-plane localization of noise and speech signals by postlingually deafened adults fitted with bilateral cochlear implants. Ear Hear 2007; 28: 524-41. [CrossRef]

25. Dillon MT, Buss E, Rooth MA, King ER, Deres EJ, Buchman CA, et al. Effect of cochlear implantation on quality of life in adults with unilateral hearing loss. Audiol Neurootol 2017; 22: 259-71. [CrossRef] 